\title{
Comparison of Four Global Sustainable Building Rating Systems Carried out With Focus on Hot and Dry Climate
}

\author{
Hind Abdel Moneim Khogali ${ }^{1,2}$ \\ ${ }^{1}$ Architecture Department, Dar Al Uloom University, KSA, Riyadh, Saudi Arabia \\ ${ }^{2}$ Future University, Khartoum, Sudan \\ Correspondence: Hind Abdel Moneim Khogali, Architecture Department, Dar Al Uloom University, KSA, \\ Riyadh, Saudi Arabia. E-mail: ahind@dau.edu.sa
}

Received: October 7, 2015 Accepted: November 12, 2015 Online Published: January 31, 2016

doi:10.5539/jsd.v9n2p1

URL: http://dx.doi.org/10.5539/jsd.v9n2p1

\begin{abstract}
Several assessment programmes has been developed worldwide on the environmental and energy effect of buildings. The aim of this study is to identify the main and sub categories of sustainable design. The researcher has investigated and compared four global building rating systems, namely leadership in Energy and Environmental Design (LEED) in USA, Emirates Green Building Rating System (ESTIDAMA) in Abu Dhabi city, Qatar Sustainability assessment System (QSAS) in the State of Qatar and Australian green Star rating system (AGBC rating system), in Australia. This paper focuses mainly on their processes, contents, similarities and differences, processes, evaluation, their development and wither these systems are applicable to all environments?

The paper outlined six main categories developed by these global rating systems being: Sustainable site, indoor environmental quality, materials, water efficiency, power supply system and innovations. Sub categories were added according to their social, cultural, economical and legislations conditions.
\end{abstract}

The paper recommended adding four main categories suitable to hot and dry climate.

Keywords: LEED system, ESTIDAMA system, QSAS system and Australia green star system, similarities and differences categories, categories for hot dry climate

\section{Introduction}

\subsection{Definition of Rating System}

Rating systems have become a universal trend, many countries around the word apply the rating system on building construction, and it is defined by the leader in energy and environment (LEED) as:

'Rating systems are groups of requirements for projects that want to achieve LEED certification. Each group is geared towards the unique needs of a project or building type'. (Council, 2014)

Another definition provided by South Africa Green Building Council which is:' the rating system sets out $a$ "menu" of all the green measures that can be incorporated into a building to make it green. Points are awarded to a building according to which measures have been incorporated, and, after appropriate weighting, a total score is arrived at, which determines the rating'. (Council, 2013).

\subsection{The Previous Studies}

The first study has been presented by (WAN, 2014) LEED in a paper on Energy Star, Green Globes, BREAM, CASBEE, NABERS, High quality environmental standards, HK BEAM, Green mark Scheme, GB Tools, AND GBI. The paper discussed each system process, content, main categories, issues and rationalizing the GBI system in Malaysia.

The second study prepared by (Fenner, March-2008) to discuss LEED and BREAM tackling the main categories and rating method, cost assessment, accessibility vision for future. (Thaimosy, 2006) prepared the third study in which he has provided deep analysis of the development of LEED and Green Globes, and analysed the LCA, a preliminary assessment of the environmental relevance. The forth study prepared by (Fowler, July-2006) and 
came in a report providing deep analysis to LEED, CASBEE, GB Tools, Green Globes and LEED. The report have revised the methods usability, durability, main categories, rating and process, applicability and development, usability, system maturity, technical content, measurability. The sixth study has been a paper prepared by (Haapio, 2007), the paper studied the existing environmental assessment tools, the main categories, assessed buildings, users of tools.

\subsection{The Methods}

\subsubsection{United Arab Emirates Green Building Rating System in Dubai}

The Emirates Green Building Council (EGBC) has been formed in 2006, with the purpose of advancing the green building principles for environmental protection and ensuring sustainability in the United Arab Emirates, today (EGBC) is actively supporting the UAE to be one of the five global leaders helping to reduce the ecological footprint of the sustainable building environment by 2015. (Council, 2007)

\subsubsection{Estidama Assessment System}

Established in 2008 by The Abu Dhabi Urban Planning Council (UPC) and has been internationally recognized for large-scale sustainable urban planning and for rapid growth.

"ESTIDAMA" is the Arabic word for sustainability,it is an initiative developed and promoted by the UPC. ESTIDAMA is the intellectual legacy of the late Sheikh Zayed bin Sultan Al Nahyan and a manifestation of his visionary governance promoting thoughtful and responsible development, while creating a balanced society based on the four equal pillars of sustainability: environmental, economic, social, and cultural. ESTIDAMA goal is to preserve and enrich the physical and cultural identity of Abu Dhabi, while creating an always-improving quality of life for its residents.

The early foundations and aspirations of ESTIDAMA are incorporated into Abu Dhabi vision 2030 and other UPC policies such as the Development Code. ESTIDAMA has been created eight years ago (2008) as the first program of its kind tailored to the Middle East region environment. In the immediate term, ESTIDAMA is focused on the rapidly changing built environment. In this regard the UPC is making significant strides to influence projects under design, development or construction within the Emirate of Abu Dhabi. An essential tool to advance ESTIDAMA is the Pearl Rating System, specifically tailored to the hot climate and arid environment of Abu Dhabi, by supporting the social, cultural traditions and Abu Dhabi cultural values. All new projects must achieve a minimum 1 Pearl rating to receive the approval of the planning and permitting authorities. Government funded buildings must achieve 2 Pearl rating as minimum. (Council, 2010)

\subsection{Qatar Sustainability Assessment System (QSAS)}

Has been started in 2007 to create a sustainable built environment minimizes ecological impact while addressing the specific regional needs and environment of Qatar. The built environment contributes to air pollution exposure, land use and contamination, fossil fuel depletion, water depletion, materials depletion, impacts on human health, and climate change. Responsible design, construction and building operations can mitigate the negative effects of the built environment. QSAS started in 2007. (Diar, Oct. 2010) presented a paper in NGO PANEL SESSION: Focusing on the vital role played by NGO's to encourage organizations to act sustainably and raise awareness of green issues in the Kingdom Saudi Arabia.

CASE STUDY: Developing a sustainability rating system in the GCC countries: Qatar Experience: represents an overview of the region's first performance based sustainability rating system, Qatar Sustainability Assessment System (QSAS) as a model. The system consists of eight main categories which are: management, culture and economic value, water, energy, material, human comfort and indoor environmental quality. Today 1000s building designed under this system illustrating the rating system. The research programs included, but not limited to:

$$
\begin{aligned}
\text { I. energy conservation and efficiency, } \\
\text { II. } \\
\text { III. materials, water, } \\
\text { IV. }
\end{aligned}
$$

\subsection{Leadership in Energy and Environmental Design (LEED)}

LEED, or Leadership in Energy and Environmental Design, is an internationally recognized green building certification system. Developed by the U.S. Green Building Council (USGBC) in March 2000, LEED 
provides building owners and operators with a framework for identifying and implementing practical and measurable green building design, construction, operations and maintenance solutions.

(City, 2011) This system explicitly allows environmental and social factors, including site, water, energy, materials, and indoor air quality, to be weighed side by side with financial metrics in the design process. The growth of the USGBC is a testament to the exploding interest in ecological approaches to building design. USGBC membership has grown tenfold since 2000, and now includes over 6,300 companies and organizations. (Haselbach. L., 2008), presented introduction to sustainable construction and discussed LEED system and principles. United States Green Building Council USGBC (Council, 1996) discussed the environmentally sustainable development main issues

\subsection{Green Star Rating System of the Green Building Council of Australia}

Green Star is a comprehensive, national, voluntary environmental rating scheme that evaluates the environmental design and achievements of buildings. Green Star was developed for the property industry in order to:

Establish a common language, set a standard of measurement for green buildings, promote integrated, whole-building design; recognize environmental leadership, Identify building life-cycle impacts; and raise awareness of green building benefits. Green Star covers a number of categories that assess the environmental impact that is a direct consequence of a projects site selection, design, construction and maintenance. The nine categories included within all Green Star rating tools are: Management, Indoor Environment Quality, Energy, Transport, Water, Materials, Land Use \& Ecology, Emissions, Innovation (Australia, 2015).

\section{Objectives}

1) To identify the definition of the rating system

2) To introduce the International Sustainable Rating systems that will be discussed in this study: LEED V4, AUSTRALIA GREEN STAR BUILDING RATING SYSTEM (AGB), ESTIDAM and QSAS.

3) To study and discuses the systems in process, categories, sub issues, development, applicability, more similarities and differences.

4) To suggest additional category that is important for hot dry climate and not implemented by the global methods.

5) To give guide line to sustainable assessment method for hot dry climate

\section{Methodology and Sub Headings}

The methodology begins by literature review of the previous studies to study and compare between four international sustainable assessment methods which are LEED V4, AUSTRALIA GREEN STAR BUILDING RATING SYSTEM (AGB), ESTIDAM and QSAS. The documents are available through their websites. Then; method of presentation is presented in tables and figures to identify the main categories of each system, sub issues, process, method of evaluation, and the certificate levels. This has been followed by; deep analysis and discussion of the main categories: Sustainable site, indoor environment, energy, water and materials to identify the similarities and differences. The second part of the study focuses on studying the additional categories suitable to hot dry climate. The study outlines the main categories which should be implemented by any international sustainable building rating system with respect to environmental, social, economical aspects and identifying the additional categories suitable to hot dry climate.

\section{Result/Findings}

I. The comparison shows that there are similar Categories shared between the four global rating systems, LEED, Australia Green Star rating system, ESTIDAMA and QSAS, namely: Sustainable Site, Indoor environmental quality, Energy, water material and innovation.

II. As well; there are additional categories introduced by these global systems:

Australia green star system provided new additional categories, which are management, transportation and land ecology. ESTIDAMA added: Urban community, Culture and economic value, integrated development process. QSAS: Culture and economic value. The system added these new categories aiming to connect the design with local culture, economic and local community and local environment.

III. There are similarities and differentiations observed in each Category existing in the main issues, and which are attributed to the deference in location, environmental conditions, natural resources, culture, and economic aspects. 
IV. The total points of LEED v4 are (110 points), Australia (100 points), ESTIDAMA (159 points), and QSAS has $(100,500,1000$ points).

LEED uses points in evaluation and the categorization ranges from silver, Gold, Platinum. GBA uses Star Rating System and the categorization range from one star to six stars, ESTIDAMA uses Pearl rating system and the categorization range from one pearl to six pearl and QSAS uses star rating system.

V. Each system has a certain process identified in their website; LEED certification involves five primary steps: Determine which rating system used, Registration of project, Submission of certification application and paying a certification review, await the application review, receive the certification decision. Green Star Certification uses a formal process which involves a project using a Green Star rating tool to guide the design or construction process during which documentation. The Green Building Council of Australia will commission a panel of third-party Certified Assessors to validate the documentation and there are two rounds of Assessment available to a project for which to achieve validation of credits claimed. The Development Review Process has been introduced by Dhabi Urban Planning Council (UPC) to provide a streamline process for reviewing development proposals. In QSAS the process starts by submission of the project, preliminary review, appealing of the certifying body's decision, final review and Certification.

VI. Sustainable site similarities are: heat island effect and -site development; on the other hand the differences in LEED V4 site assessment, site development, open space, rain water management, heat island reduction and light pollution reduction. QSAS has added more additional issues in site category like Ecological Value of Land; ESTIDAMA and Australia rating system: does not have sustainable site.

VII. In the Indoor Environment the similarities increase: Ventilation Construction, Low-Emitting Materials, Composite Wood \& Agrifiber Products, Daylight \& Views, Daylight $75 \%$ of Spaces, Thermal Comfort. On the other hand; in LEED V4 the differences minimize: indoor performance, environmental tobacco control, enhance indoor air quality control, low emitting materials, thermal comfort, day lighting, views and acoustic performance. Australia rating system added HVAC system and pollutants. QSAS added Monitoring air temperature and quality and adjusting or calibrating as appropriate and Mechanical ventilation.

VIII. In Energy the similarities are: Optimize Energy Performance, On-Site Renewable Energy, Measurement \& verification green power. On the other hand; the differences in LEED V4 are: Fundamental commissioning and verification, minimum energy performance, energy metering, renewable energy, refrigerant management and green power. Australia rating system added HVAC System Simulations, building Envelope, A/C Pumping, and Modelling Information. ESTIDAMA added Community Energy Strategy, Building Energy Guidelines, Energy monitoring and reporting and Community Strategies for Passive Cooling, QSAS added Energy Demand Performance, Energy Delivery Performance, and Fossil Fuel Conservation.

IX. In water the similarities are: water Efficient Landscaping, Water Use Reduction. On the other hand; the differences in LEED V4 are: outdoor water use reduction, indoor water use reduction, water metering and cooling tower water use. Australia rating system added solar collectors, Hot water rating load, Measurements, water reuse. ESTIDAMA added Community Water Strategy, Building Water Guidelines and Water Monitoring. QSAS: added Water Consumption.

X. In materials the similarities are: Construction Waste Management, Materials Reuse, Recycled Content, Regional Materials, and Certified Wood. On the other hand; the differences in LEED V4 are: construction waste management planning, building life cycle analysis, environmental products, use of raw materials, Australia rating system added Eco content, durability, environmental management system. ESTIDAMA added Basic Construction Waste Management, Reused or Certified Timber. QSAS added recycling content and regional building materials.

XI. The logic of rating system is open mind for all specialists who can share solutions by their experience and specialization.

XII. The conclusion arrived at through this analysis, is that rating system is an ever-evolving process, and its improvement depends on the best practice of users and experts. In each version we have more challenges and the total points are increased to achieve a higher certificate

XIII. As a matter of fact; it contains sub issues that help in managing a certain local and global problems, for example, local problems: storm water design in Sustainable site category; and for global problems, examples are: that have an effect on the local environment heat island effect, smoke control, optimize energy performance.

XIV. By this comparison, we can fix five main categories for sustainable eco buildings, which are sustainable site, Energy, water, material, indoor environmental control. 
XV. More categories, suitable to our local environmental conditions, could be added e.g.: culture, social aspect and local legislations. The issues are detailed according to our local interest and environmental problems visualized for Greater Khartoum as the case study lays in hot dry climate. The research give a frame work for assessment method suitable to hot dry climate such as Greater Khartoum. In addion to the five basic categories: sustainable site, indoor environmental quality, water efficiency, energy efficiency and material. The research outlines the following categories:

15.1 A category about health and safety procedure could been added as an important aspect. It is extremely important to add Health, Safety and Environment as new Category. Only green star rating system and ESTIDAMA adds land ecology as an important category. *Only ESTIDAMA and QSAS included the outdoor environment as important category in 2010.

15.2 It is very important to include Outdoor thermal control as a new Category. Improving of the outdoor environment is imperative in Sudan as it provides thermal control, and it can be achieved by provision of sheds, terraces, balconies, swimming pools, fountains; maximizing outdoor space for its physiological, ecological , economic and social effect as specified, and in order to make the air more humid and comfortable.

15.3 The environmental design process as important category. It is very important to add Environmental Design Process in all design process.

15.4 The research recommended studying building form as an important category. Studying of building form according to site location and local environmental conditions and solar angle will provide more shades to the building and will minimize the solar radiation absorbed by the walls and minimizes air temperature around the house. Researchers found that L-shape and U-shape forms, both are more effective in hot dry climate. Form can be studied on cultural and social basis, taking into consideration the courtyard system. In this respect, researches have approved that courtyard system contributes to cooling down air temperature during daytime, and minimizes radiation, technological aspect may be added.

15.5 Studding of culture and economic value, it is essential to add Community aspect as community participation, social aspect, culture aspect and economic value.

15.6 The research recommends that all types of projects, applicable, durable, developed by government, private sector, industry, NGOs and provide continuous review through using of experts opinions, durable for long time and provide LCA, by providing durable eco building materials, re-use, recycling, re-processing contents.

\section{Analysis and Discussion}

The discussion contain two main part

Part one:

Discuss four global systems in: the main process, method of evaluation, the total points in each categories, the process, the certificate level, the main categories, sub issues, similarities and differences, additional categories was added by the global assessment methods, availability, applicability and development.

Part two:

discuss additional categories suitable to hot dry climate.

\subsection{Part One: Dicuss of 4 Global Sustainable Assessment Methods}

\subsubsection{The Main Category}

According to Table 1, we can conclude:

Table 1. The main categories of the systems

\begin{tabular}{lllll}
\hline The main Categories & LEED v4 & Australia green star rating system & Steadman & QSAS \\
\hline Sustainable Site & $\bullet$ & $\bullet$ & 0 & $\bullet$ \\
Indoor environmental quality & $\bullet$ & $\bullet$ & 0 & $\bullet$ \\
Energy and atmosphere & $\bullet$ & $\bullet$ & $\bullet$ & $\bullet$ \\
Water Efficiency & $\bullet$ & $\bullet$ & $\bullet$ & $\bullet$ \\
Material and resources & $\bullet$ & $\bullet$ & $\bullet$ & $\bullet$ \\
Innovation in design & $\bullet$ & $\bullet$ & $\bullet$ & $\bullet$
\end{tabular}




\begin{tabular}{|c|c|c|c|c|}
\hline Regional priority & $\bullet$ & ○ & ० & ○ \\
\hline Management and operation & ○ & $\bullet$ & ○ & $\bullet$ \\
\hline Transportation & ○ & $\bullet$ & ० & ○ \\
\hline Land Ecology & ○ & $\bullet$ & $\circ$ & ○ \\
\hline Urban community & ○ & ○ & $\bullet$ & $\bullet$ \\
\hline Culture and economic value & ○ & ○ & $\circ$ & $\bullet$ \\
\hline Integrated development process & O & ○ & $\bullet$ & ○ \\
\hline Natural system & O & O & $\bullet$ & ○ \\
\hline
\end{tabular}

- Means its applicable

○ Means it's not applicable

I. LEED provides six main categories, which are sustainable site, indoor environmental quality, energy and atmosphere, water efficiency, materials and resources and innovation in design.

II. Australia green star rating system provides nine main categories which are sustainable site, indoor environmental quality, energy and atmosphere, water efficiency, materials and resources, innovation in design, management and operation, transportation and land ecology.

III. ESTIDAMA rating system provides seven main categories, which are energy, water, material, innovation, urban community, culture and economic value, integrated development process and natural system.

ESTIDAMA rating system adds urban community, integrated development process and natural system.

Urban community:

- The Liveable Communities section is intended to encourage responsive design and sustainable land use.

- through the following:

- Thorough analysis and assessment of the social, economic, design and policy context.

- Provision of community facilities in the right place, time and at the right level.

- $\quad$ Analysis and appreciation of the climatic conditions.

- The efficient and effective use of land.

- Outdoor Thermal Comfort Strategy.

Creating a community that is easy to move around by all modes including pedestrian and cycling and enables excellent connections to the wider sub region; providing for a diverse and inclusive population; and providing opportunities for commerce and trade at an appropriate level.

Abu Dhabi Urban Planning Council (Council, 2010)

Integrated development process: Sustainable building guide line, Integrated Development Strategy Sustainable Building Guidelines, Community-Dedicated Infrastructure Basic Commissioning, Life Cycle Costing, Guest Worker Accommodation Construction Environmental Management, and Sustainability Awareness.

Natural System: To minimize demand for resources, promote soil protection and enhancement and ensure the long-term survival and management of landscaped / habitat areas.

IV. QSAS rating system consists of nine main categories, which are sustainable site, indoor environmental quality, energy, water, material, innovation, management and operation, urban community and culture and economic value.

The similarity categories are sustainable site, indoor environmental qualities, energy, water, materials and innovation in design.

The differences are the Australia green star rating system added; management and operation, transportation and land ecology.

Management and operation: Credits address the adoption of sustainable development principles from project conception through design, construction, commissioning, tuning and operation 
Transportation: Credits reward the reduction of demand for individual cars by both discouraging car commuting and encouraging use of alternative transportation.

Land ecology: Credits address a project's impact on its immediate ecosystem, by discouraging degradation and encouraging restoration of flora and fauna.

QSAS rating system added urban community and culture and economic value.

The community: Consists of factors associated with cultural conservation

And support of the local economy.

Culture and economic value: Consists of factors associated with the urban environment such as zoning, transportation networks and loadings. Loadings on the urban environment include traffic congestion and air, noise, and light pollution. (Diar, Oct. 2010).

\subsubsection{Method of Evaluation}

Each system has it is own method of evaluation some are points others are weighing:

Table. 2 presents the method of evaluation of the Systems:

Table 2. Method of evaluation of the systems

\begin{tabular}{|c|c|c|c|c|c|}
\hline \multirow[t]{3}{*}{$\begin{array}{l}\text { Method } \\
\text { evaluation }\end{array}$} & & \multirow[t]{2}{*}{$\begin{array}{l}\text { LEED } \\
\text { System } \\
\end{array}$} & \multirow[t]{2}{*}{$\begin{array}{l}\text { Australia green star rating } \\
\text { system }\end{array}$} & ESTIDAMA & QSAS \\
\hline & & & & & Weighing \\
\hline & & points & Star rating system & $\begin{array}{l}\text { Pearl } \\
\text { system }\end{array}$ & $\begin{array}{l}\text { And QSAS star } \\
\text { system }\end{array}$ \\
\hline
\end{tabular}

LEED uses points, GBA uses Star Rating System, ESTIDAMA uses Pearl rating system and QSAS uses QSAS star system.

\subsubsection{The Total Points of Each Category on Each System}

\section{LEED V4:}

Table 3 shows the total points of each category LEED V4 concluded as follows:

Table 3. The total points of each category on LEED V4

\begin{tabular}{lc}
\hline LEED V 4: & \\
\hline Location & 16 \\
Sustainable Site & 10 \\
Indoor Environmental Quality & 16 \\
Water efficiency & 11 \\
Energy and atmosphere & 33 \\
Material & 13 \\
Innovation & 6 \\
Regional priority & 4 \\
Total points & 110 \\
\hline
\end{tabular}

Source: usgbc.org

LEED V.4 provides points to evaluate each category, location (16), sustainable site (10), indoor environmental quality (16), water efficiency (11), energy and atmosphere (33), material (13) innovation (6) Regional priority (4). They give load and more challenges to energy and atmosphere and indoor environmental quality. Moderate 
points are given to location, sustainable site and materials and less point to water efficiency and innovation and regional priority.

\section{Australia Green Star Rating System}

Table 4 shows the evaluation method is staring system and its range, one star (10-19), two star (20-29), three star (30-44), four star (45-59), five star (60-74), six star (75+). The certified project starts from three stars.

Table 4. Australia green star rating system points of each category

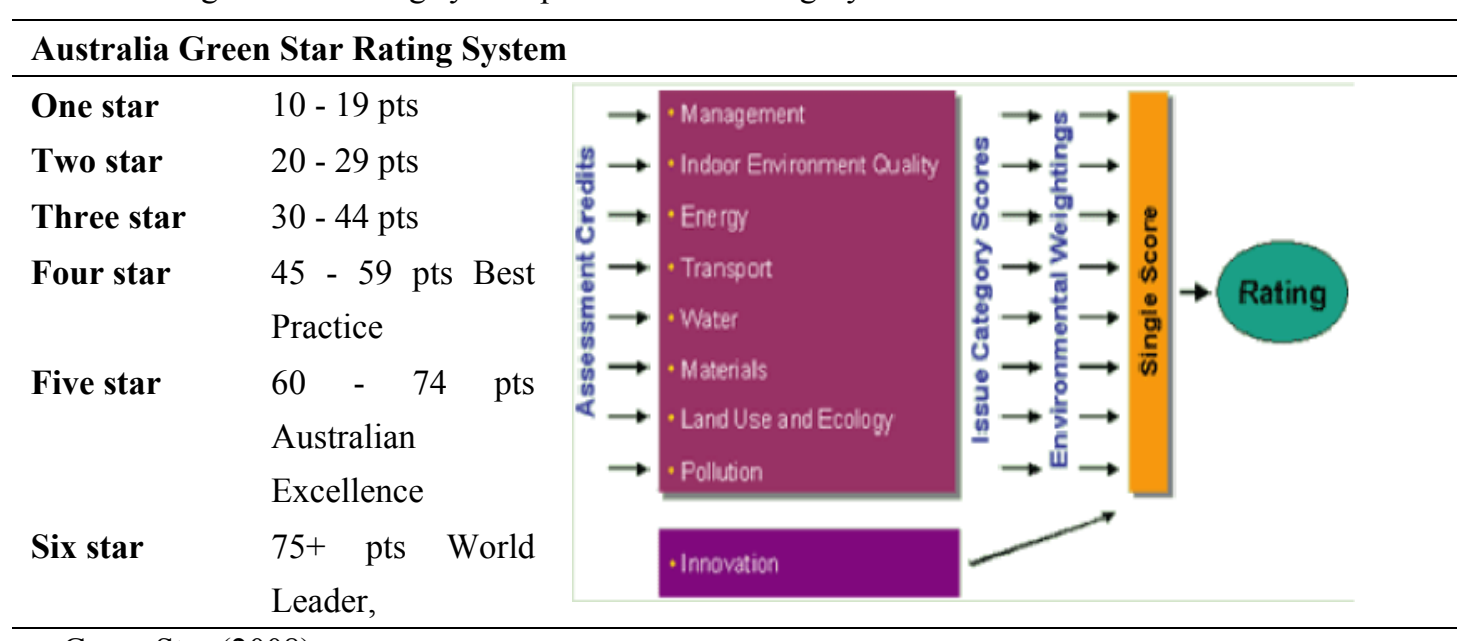

Source: Green Star (2008)

\section{ESTIDAMA}

Table 5 shows the total points of each main category for ESTIDAMA and concluded as follows: ESTIDAMA, points also are used to evaluate each category, integrated development process (10), Natural system (14), livable communities (38), precious water (37), resourceful energy (42), stewarding materials (18) and innovation (3). They give load and more challenges to livable communities, water and energy. Moderate points are given to natural systems and stewarding materials. And less point are given to integrated development process and innovation.

Table 5. ESTIDAMA total points of each main category

\begin{tabular}{|c|c|}
\hline \multicolumn{2}{|l|}{ ESTIDAMA } \\
\hline Integrated Development Process & 10 \\
\hline Natural Systems & 14 \\
\hline Livable Communities & 38 \\
\hline Precious Water & 37 \\
\hline Resourceful Energy & 42 \\
\hline Stewarding Materials & 18 \\
\hline Innovating Practice & 3 \\
\hline Total & 159 \\
\hline
\end{tabular}

Source: (Council, 2010)

\section{QSAS}

Table 6 shows the total weight of each category on QSAS concluded as follows: 
Table 6. QSAS Total weight for each category

\begin{tabular}{|c|c|c|c|c|}
\hline \multicolumn{5}{|l|}{ QSAS total weight: } \\
\hline Urban community & 0.24 & & & \\
\hline Site & 0.27 & Urtana comentectivy & 0.12 & \\
\hline Energy & 0.72 & Ste & $D_{0.015}$ & \\
\hline water & 0.48 & Watar & 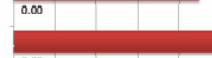 & som \\
\hline Material & 0.24 & Materials & $\infty_{0 \infty}^{\infty}$ & \\
\hline Indoor Environmental Quality & 0.42 & Indobre Fnviromment & 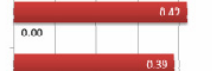 & \\
\hline Culture and economic value & 0.39 & & & \\
\hline Management and operation & 0.24 & & & \\
\hline
\end{tabular}

Source: (Alhor, 2009)

QSAS provides urban community (0.24), Site (0.27), Energy (o.72), water (0.48), indoor environmental quality $(0.42)$, culture and economic value $(0.39$, management $(0.24)$.

\subsubsection{The Process}

\section{i. LEED PROCESS}

\section{LEED certification involves five primary steps}

1 Determine which rating system used and prepare your certification application. Applications differ depending on the building type and the LEED credits decided to pursue.

2 Register your project. Registration is a flat fee paid up front at the time of registration; rates are based on the date of registration. The certification fee is based on your project's rating system and size; it is calculated and paid when the project team submits documentation for review in LEED Online.

3 Submit your certification application and pay a certification review fee. Fees differ according to building type and square footage.

4 Await the application review. Review processes differ slightly for each building type.

5 Receive the certification decision, which you can either accept or appeal. An affirmative decision signifies that your building is now LEED certified. www. usgbc.org

\section{ii. GBC OF AUSTRALIA PROCESS}

1. Green Star Certification is a formal process which involves a project using a Green Star rating tool to guide the design or construction process during which a documentation-based submission is collated as proof of this achievement.

2. The Green Building Council of Australia will commission a panel of third-party Certified Assessors to validate that the documentation for all claimed credits is in adherence with the Compliance Requirements as outlined in the Technical Manual that accompanies each rating tool.

3. There are two rounds of Assessment available to a project in which to achieve validation of credits claimed. Project teams are notified of their score based on the recommendation of the Assessment Panel and, where applicable, of any innovation credits that have been awarded by the GBCA. If a Certified Rating is awarded, the project will receive a framed certificate, award letter marketing kit and relevant Green Star logos Projects types on table.

\section{iii. ESTIDAMA PROCESS}

The relationship existing between the UPC Development Review Process, ESTIDAMA, the Pearl Rating System and the Development Review Process has been introduced by Dhabi Urban Planning Council (UPC) to provide a streamline process for reviewing development proposals. The process comprises four steps: Enquiry, Pre-Concept Stage, Concept Planning Review and Detailed Planning Review. The UPC uses this review process for two main purposes: To ensure that the development proposals comply with the Emirate's urban planning policies (e.g. land uses, Densities, ESTIDAMA). To coordinate the review and approval of development 
applications by external government agencies.

\section{iv. QSAS WEB PROCESS}

Project Status: Identifies the project's current phase in the assessment process.

Submission in Progress: In this phase, criteria are assigned to team members on the Project Home, and supporting documentation for each criterion is uploaded by the project team on the Criterion Home.

Preliminary Review: After the submittal of the design criteria, the certifying body will notify the project manager of any insufficient or incomplete criteria documentation. Failure to resubmit correct documentation will result in a score of -1 for that criterion. The preliminary review phase is also the time for the design team to submit any questions to the certifying body that are outside of the scope of any QSAS prescriptive approaches or calculators. The certifying body will provide guidance on the approach to be taken to complete the assessment of the criterion.

Appeals: The project team may choose to appeal the certifying body's decision in regards to the scoring of a specific criterion after the final review process. The applicant must, via the appeals process, provide sufficient proof that the criterion should score differently. The project will pay a fee for each criterion appeal. All appeals must be submitted within one month of the final review of the project's design phase criteria.

\section{Final Review}

The certifier has completed the Preliminary Review. Any criteria marked "resubmit" is resubmitted by the project team for a Final Review by the certifying authority. In this phase, the certifier assigns the remaining criteria a score and to determine a final project score.

\section{Certification}

Final review is complete, and the project team can view the final project score. If the project team feels a score is incorrectly assigned, a criterion can be resubmitted through the appeals process. (Diar, Oct. 2010).

5.1.5 The Certificate Level

USA LEED V.4 used (certified-gold-silver-Platinum), Australia star rating system used Star rating system for QSAS used star and weighing system and ESTIDAMA used Pearl system as follows:

\section{i. LEED V4. CERTIFICATE LEVELS}

Table 7 shows the certification and the range points

Table 7. U.S.GBC"LEED" v4. Certified level

\begin{tabular}{ll}
\hline Certified & Range of points \\
\hline Certified & $40-49$ points \\
Silver: & $50-59$ points, \\
Gold & $60-79$ points, \\
Platinum & 80 Points and above \\
\hline
\end{tabular}

(40-49) certified, (50-59) silver, (60-79) Gold and 80+ Platinum

\section{ii. AUSTRALIA GREEN STAR RATING SYSTEM CERTIFICATE}

(Table. 8) shows Green Star ratings are determined by comparing a project's overall score with the following rating scale: Australia uses one star, two stars, three stars, four stars, five stars, six stars. 
Table 8. GBCA Certificate levels

Source: (Australia, 2015).

\begin{tabular}{ll}
\hline GBCA & \\
\hline One star & $10-19 \mathrm{pts}$ \\
Two star & $20-29 \mathrm{pts}$ \\
Three star & $30-44 \mathrm{pts}$ \\
Four star & $45-59 \mathrm{pts}$ Best Practice \\
Five star & $60-74$ pts Australian Excellence \\
Six star & $75+$ pts World Leader, \\
\hline
\end{tabular}

\section{iii. ESTIDAMA CERTIFICATE LEVEL:}

(Table 9) shows within each section there are both mandatory and optional credits and credit points are awarded for each optional credit achieved. To achieve 1 Pearl rating, all the mandatory credit requirements must be met. To achieve a higher Pearl rating, all the mandatory credit requirements must be met along with a minimum number of credit points.

Table 9. ESTIDAMA certificate levels

\begin{tabular}{ll}
\hline Requirement & Pearl Rating Achieved \\
\hline All mandatory credits & 1 Pearl \\
All mandatory credits +55 credit points & 2 Pearl \\
All mandatory credits +75 credit points & 3 Pearl \\
All mandatory credits +100 credit points & 4 Pearl \\
All mandatory credits +125 credit points & 5 Pearl \\
\hline
\end{tabular}

Source: (Council, 2010).

\section{iv. QSAS CERTIFICATE LEVELS.}

(Table 10) shows there are 6 certification levels in GSAS/QSAS. Level 1 being the minimum a project can achieve for passing the GSAS/QSAS assessment and Level 6 being the maximum for achieving the highest score in the GSAS/QSAS assessment.

Table 10. QSAS certificate levels

\begin{tabular}{ccc}
\hline $\begin{array}{c}\text { GSAS/QSAS } \\
\text { Certification Levels }\end{array}$ & Cumulative Score (X) & QSAS Star Rating $(\star)$ \\
\hline 1 & $0.00 \leq \mathrm{X} \leq 0.50$ & $\star$ \\
2 & $0.50<\mathrm{X} \leq 1.00$ & $\star \star$ \\
3 & $1.00<\mathrm{X} \leq 1.50$ & $\star \star \star$ \\
4 & $1.50<\mathrm{X} \leq 2.00$ & $\star \star \star \star$ \\
5 & $2.00<\mathrm{X} \leq 2.50$ & $\star \star \star \star \star$ \\
6 & $2.50<\mathrm{X} \leq 3.00$ & $\star \star \star \star \star \star$ \\
\hline
\end{tabular}

Source: (development, 2012)

Each level has an equivalent range of cumulative scores, which translates to star rating for the project. The aim for all QSAS criteria and their associated measurements is to be performance-based and quantifiable on the scale of -1 to $3(-1,0,1,2,3)$ or 0 to 3 , depending on the criterion's level of impact. This implies that every criterion should be measured in terms of a predicted outcome of the proposed design, such as a predicted load in an impact category for the environment, the depletion rate of fossil energy, the consumption of potable water, or the 
addition to the overall cultural value of the urban environment. Using negative points allows criteria with greater impact to be emphasized and to achieve a higher level of building performance. In QSAS, -1 is a negative measure of "not acceptable", and 0 is a threshold for "acceptable" or is used in the case that the requirement is not applicable. The scores of 1 to 3 are levels of gradual improvements.

Each category and criterion has an associated weight based on its relative environmental, social, and economic impact. Once a score is assigned to each criterion in the assessment system, the values are multiplied by the weight and a cumulative final score is determined. QSAS consists of six certification levels to measure the project's impact. A building that obtains a final score below 0 does not meet the baseline and will be denied certification. Certification can only be achieved when the final score is greater than or equal to 0 , earning a rating of $1,2,3,4,5$, or 6 stars. The highest score a building can achieve is 3.0 and the highest certification level is 6 stars.

5.1.6 Main Categories Sub Issues: Similarties and Differences

\section{THE SUSTAINABLE SITE:}

(Table 11) shows:

Table 11. The sustainable site

\begin{tabular}{|c|c|c|c|c|}
\hline $\begin{array}{l}\text { The Issues of each categories } \\
\text { 1.Sustainable Site }\end{array}$ & $\begin{array}{ll}\text { LEED } & \text { V4. } \\
\text { System } & \end{array}$ & $\begin{array}{l}\text { Australia green star } \\
\text { rating system }\end{array}$ & ESTIDAMA & QSAS \\
\hline Construction Activity Pollution Prevention & $\bullet$ & o & ○ & o \\
\hline Site Selection & $\bullet$ & ○ & o & o \\
\hline $\begin{array}{l}\text { Development Density \& } \quad \text { Community } \\
\text { Connectivity }\end{array}$ & • & $\circ$ & ○ & ○ \\
\hline Brownfield Redevelopment & $\bullet$ & $\circ$ & ○ & ○ \\
\hline $\begin{array}{l}\text { Alternative Transportation, } \\
\text { Transportation Access }\end{array}$ & - & ○ & o & $\circ$ \\
\hline $\begin{array}{l}\text { Alternative Transportation, Bicycle Storage } \\
\text { \& Changing Rooms }\end{array}$ & $\bullet$ & $\circ$ & ○ & $\circ$ \\
\hline $\begin{array}{l}\text { Alternative Transportation, Low-Emitting \& } \\
\text { Fuel-Efficient Vehicles }\end{array}$ & $\bullet$ & ○ & ○ & $\circ$ \\
\hline Alternative Transportation, Parking Capacity & $\bullet$ & $\circ$ & ○ & ○ \\
\hline Site Development, Protect or Restore Habitat & $\bullet$ & $\circ$ & $\circ$ & $\bullet$ \\
\hline Site Development, Maximize Open Space & $\bullet$ & $\circ$ & ○ & ○ \\
\hline Storm water Design, Quantity Control & $\bullet$ & $\circ$ & ○ & ○ \\
\hline Heat Island Effect, Non-Roof & $\bullet$ & $\circ$ & $\circ$ & ○ \\
\hline Heat Island Effect, Roof & $\bullet$ & ○ & ○ & $\bullet$ \\
\hline Light Pollution Reduction & $\bullet$ & $\circ$ & ○ & ○ \\
\hline Ecological Value of Land & ○ & $\circ$ & $\circ$ & $\bullet$ \\
\hline Land Preservation & $\circ$ & $\circ$ & ○ & $\bullet$ \\
\hline Vegetation \& Shading & ○ & $\circ$ & ○ & $\bullet$ \\
\hline Water Body Preservation & ○ & $\circ$ & ○ & $\bullet$ \\
\hline Desertification & ○ & $\circ$ & ○ & $\bullet$ \\
\hline Rainwater Runoff & ○ & ○ & ○ & $\bullet$ \\
\hline Landscape Amenities & ○ & $\circ$ & ○ & $\bullet$ \\
\hline Vegetation & $\circ$ & $\circ$ & $\circ$ & $\bullet$ \\
\hline Mix use centre. & ○ & $\circ$ & ○ & $\bullet$ \\
\hline Walk ability & $\circ$ & ○ & $\circ$ & $\bullet$ \\
\hline
\end{tabular}


The similarities in the main issues of Sustainable site category are:

-heat island effect

-site development

The differences in the main issues of sustainable site category are:

I. LEED has added more additional issues in Site Category i.e. : Construction Activity Pollution Prevention, Site Selection, Development Density \& Community Connectivity, Brownfield Redevelopment, Alternative Transportation, Public Transportation Access, Alternative Transportation, Bicycle Storage \& Changing Rooms, Alternative Transportation, Low-Emitting \& Fuel-Efficient Vehicles, Protect or Restore Habitat, Site Development, Maximize Open Space, Storm water Design, Quantity Control, Heat Island Effect, Non-Roof, Light Pollution Reduction, Green vehicles, access to quality transit, est.

II. Australia rating system: They don't have sustainable site.

III. QSAS: added more additional issues in site category which are: Ecological Value of Land, Ecological Value of Land, Land Preservation, Vegetation \& Shading, Water Body Preservation, Desertification, Rainwater Runoff, Landscape Amenities, Vegetation, Mix use centre, Walk ability.

IV. ESTIDAMA

\section{INDOOR ENVIRONMENTAL QUALITY (IQE)}

Table 12: Concluded the indoor environment as follows:

Table 12. Indoor environmental quality

\begin{tabular}{|c|c|c|c|c|}
\hline $\begin{array}{l}\text { The Issues of each categories } \\
\text { 2.Indoor Environmental Quality }\end{array}$ & $\begin{array}{l}\text { LEED V4.2 } \\
\text { System }\end{array}$ & $\begin{array}{l}\text { Australia green star } \\
\text { rating system }\end{array}$ & ESTIDAMA & QSAS \\
\hline Minimum IAQ Performance & $\bullet$ & 0 & 0 & 0 \\
\hline Environmental Tobacco Smoke (ETS) Control & $\bullet$ & ○ & ○ & ○ \\
\hline Outdoor Air Delivery Monitoring & $\bullet$ & & ○ & ○ \\
\hline $\begin{array}{l}\text { Construction IAQ Management Plan, Before } \\
\text { Occupancy }\end{array}$ & • & 0 & O & $\bullet$ \\
\hline Low-Emitting Materials, Adhesives \& Sealants & $\bullet$ & O & 0 & ○ \\
\hline Low-Emitting Materials, Paints \& Coatings & $\bullet$ & ○ & ○ & ○ \\
\hline Low-Emitting Materials, Carpet Systems & $\bullet$ & ○ & ○ & ○ \\
\hline $\begin{array}{l}\text { Low-Emitting Materials, Composite Wood \& } \\
\text { Agrifiber Products }\end{array}$ & $\bullet$ & 0 & ○ & 0 \\
\hline Indoor Chemical \& Pollutant Source Control & $\bullet$ & ○ & ○ & $\bullet$ \\
\hline Controllability of Systems, Lighting & $\bullet$ & ○ & ○ & ○ \\
\hline Controllability of Systems, Thermal Comfort & ○ & ○ & & $\bullet$ \\
\hline Thermal Comfort, Design & - & ○ & O & ○ \\
\hline Thermal Comfort, Verification & $\bullet$ & ○ & ○ & ○ \\
\hline Daylight \& Views, Daylight $75 \%$ of Spaces & $\bullet$ & & ○ & $\bullet$ \\
\hline Daylight \& Views, Views for $90 \%$ of Spaces & $\bullet$ & $\bullet$ & ○ & $\bullet$ \\
\hline HVAC System & $\bullet$ & $\bullet$ & ○ & $\bullet$ \\
\hline pollutants & ○ & $\bullet$ & ○ & ○ \\
\hline $\begin{array}{l}\text { Monitoring air temperature and quality and } \\
\text { adjusting or calibrating as appropriate }\end{array}$ & ○ & - & 0 & 0 \\
\hline Maximizing views to the exterior for all occupants & 0 & O & O & $\bullet$ \\
\hline $\begin{array}{l}\text { Providing for occupant comfort by minimizing } \\
\text { glare }\end{array}$ & ○ & 0 & 0 & $\bullet$ \\
\hline
\end{tabular}


Controlling the amount of noise produced by or transferred from the building interior and exterior

Mechanical ventilation

Indoor Chemical \& Pollutant Source Control

Views

Illumination Levels

Acoustic Quality

Daylight

$\begin{array}{llll}\circ & 0 & 0 & \bullet \\ 0 & 0 & 0 & \bullet \\ 0 & 0 & 0 & \bullet \\ 0 & 0 & 0 & \bullet \\ 0 & 0 & 0 & \bullet \\ 0 & 0 & 0 & \bullet \\ 0 & 0 & 0 & \bullet \\ 0 & 0 & 0 & \bullet\end{array}$

Construction IAQ Management Plan, Before Occupancy

The similarities in the main issues of Indoor environment category are: Increased Ventilation Construction, Low-Emitting Materials, Composite Wood \& Agrifiber Products, Daylight \& Views, Daylight $75 \%$ of Spaces, Thermal Comfort and Verification.

The differences in the main issues of Indoor environment category are:

I. LEED: has added more additional issues in Control indoor environment Category which are: Minimum IAQ Performance, Environmental Tobacco Smoke (ETS) Control, Outdoor Air Delivery Monitoring, Construction IAQ Management Plan, Before Occupancy, Indoor Chemical \& Pollutant Source Control, Views, Illumination Levels, Acoustic Quality, Daylight, indoor construction plan, thermal comfort, quality views and acoustic performance.

II. Australia: New additional points has been added which are essential for contemporary design on shopping malls, educational and office buildings: HVAC system and pollutants.

III. ESTIDAMA: None.

IV. QSAS: has added additional points which are: Monitoring air temperature and quality and adjusting or calibrating as appropriate, Maximizing views to the exterior for all occupants, Mechanical ventilation, Indoor Chemical \& Pollutant Source Control, Illumination Levels, Acoustic Quality, Daylight.

\section{ENERGY AND ATMOSPHERE:}

The Table 13: Concluded that the Energy is as follows:

Table 13. Energy and atmosphere

\begin{tabular}{|c|c|c|c|c|}
\hline $\begin{array}{l}\text { The Issues of each categories } \\
\text { 2-Energy and Atmosphere }\end{array}$ & $\begin{array}{l}\text { LEED } \\
\text { V4 }\end{array}$ & $\begin{array}{l}\text { Australia green star } \\
\text { rating system }\end{array}$ & ESTIDAMA & QSAS \\
\hline $\begin{array}{l}\text { Fundamental Commissioning of the Building } \\
\text { Energy Systems }\end{array}$ & - & $\circ$ & ○ & $\circ$ \\
\hline Minimum Energy Performance & $\bullet$ & ○ & o & ○ \\
\hline Fundamental Refrigerant Management & • & $\circ$ & ० & $\circ$ \\
\hline Optimize Energy Performance & $\bullet$ & $\bullet$ & ० & $\circ$ \\
\hline On-Site Renewable Energy & $\bullet$ & - & $\bullet$ & $\circ$ \\
\hline Enhanced Commissioning & - & ○ & ० & $\circ$ \\
\hline Measurement \& Verification & $\bullet$ & - & ० & $\circ$ \\
\hline Green Power & $\bullet$ & $\bullet$ & ० & $\circ$ \\
\hline HVAC Controls & ○ & $\bullet$ & ० & ○ \\
\hline HVAC System Simulations & ○ & $\bullet$ & ० & $\circ$ \\
\hline Building Envelope & ○ & $\bullet$ & ○ & $\circ$ \\
\hline A/C Pumping & $\circ$ & - & o & $\circ$ \\
\hline
\end{tabular}


Modelling Information

Community Energy Strategy

Building Energy Guidelines

Energy Monitoring and Reporting

Community Strategies for Passive Cooling

Efficient Infrastructure: District Cooling

Efficient Infrastructure: Smart Grid Technology

Renewable Energy: Offsite

Energy Efficient Buildings

Energy Demand Performance

Energy Delivery Performance

Fossil Fuel Conservation

$\mathrm{CO}_{2}$ Emissions

NOX, SOX, \& Particulate Matter

\begin{tabular}{llll}
0 & $\bullet$ & 0 & 0 \\
0 & 0 & $\bullet$ & 0 \\
0 & 0 & $\bullet$ & 0 \\
0 & 0 & $\bullet$ & 0 \\
0 & 0 & $\bullet$ & 0 \\
0 & 0 & $\bullet$ & 0 \\
0 & 0 & $\bullet$ & 0 \\
0 & 0 & $\bullet$ & 0 \\
0 & 0 & $\bullet$ & \\
0 & 0 & 0 & $\bullet$ \\
0 & 0 & 0 & $\bullet$ \\
0 & 0 & 0 & $\bullet$ \\
0 & 0 & 0 & $\bullet$ \\
0 & 0 & 0 & $\bullet$ \\
\hline
\end{tabular}

The similarities in the main issues of Energy category are: Optimize Energy Performance, On-Site Renewable Energy, and Measurement \& Verification

Green Power.

The differences in the main issues of Energy category are:

I. LEED: added more additional issues in Energy and Atmosphere Category which are:

Commissioning of the Building Energy Systems, Minimum Energy Performance, Fundamental Refrigerant Management, Optimize Energy Performance, energy metering, enhance commissioning, renewable energy, green power, refrigerant management.

II. Australia: added new additional issues which are essential on contemporary design on shopping malls, educational and office buildings: HVAC system, HVAC System Simulations, Building Envelope, A/C Pumping, Modelling Information.

III. ESTIDAMA: added new additional issues in Energy and Atmosphere Category which are: Community Energy Strategy, Building Energy Guidelines, Energy Monitoring and Reporting, Community Strategies for Passive Cooling, Efficient Infrastructure: District Cooling, Efficient Infrastructure: Smart Grid Technology, Renewable Energy: Offsite, Energy Efficient Buildings.

IV. QSAS: added additional issues in Energy which are: Energy Demand Performance, Energy Delivery Performance, Fossil Fuel Conservation, Fossil Fuel Conservation, $\mathrm{CO}_{2}$ Emissions, NOX, SOX, \& Particulate Matter.

\section{WATER EFFICIENCY:}

(Table 14): Concluded the water efficiency as follows:

Table 14. The water efficiency

\begin{tabular}{|c|c|c|c|c|}
\hline $\begin{array}{l}\text { The Issues of each categories } \\
\text { 4-Water }\end{array}$ & $\begin{array}{l}\text { LEED V4. } \\
\text { System }\end{array}$ & $\begin{array}{l}\text { Australia green star } \\
\text { rating system }\end{array}$ & ESTIDAMA & QSAS \\
\hline $\begin{array}{l}\text { Water Efficient Landscaping, Reduce by } \\
50 \%\end{array}$ & • & $\circ$ & $\bullet$ & $\circ$ \\
\hline $\begin{array}{l}\text { Water Efficient Landscaping, No Potable } \\
\text { Use or No Irrigation }\end{array}$ & $\bullet$ & $\circ$ & $\bullet$ & ○ \\
\hline Innovative Wastewater Technologies & $\bullet$ & ○ & $\circ$ & $\circ$ \\
\hline Water Use Reduction, $20 \%$ Reduction & $\bullet$ & $\circ$ & • & ○ \\
\hline
\end{tabular}


Water Use Reduction, 30\% Reduction

\section{Solar collectors}

Hot water rating load

\section{Measurements}

water reuse

Community Water Strategy

Building Water Guidelines

Water Monitoring \& Leak Detection

Community Water Use Reduction

Community Water Use Reduction: Heat

Rejection

Community Water Use Reduction: Water

Features

Storm water Management

Water Efficient Buildings \& Plots

Water Consumption

\begin{tabular}{llll}
$\bullet$ & 0 & 0 & 0 \\
0 & $\bullet$ & 0 & 0 \\
0 & $\bullet$ & 0 & 0 \\
0 & $\bullet$ & 0 & 0 \\
0 & $\bullet$ & 0 & 0 \\
0 & 0 & $\bullet$ & 0 \\
0 & 0 & $\bullet$ & 0 \\
$\bullet$ & 0 & $\bullet$ & 0 \\
$\bullet$ & 0 & $\bullet$ & 0 \\
$\bullet$ & 0 & $\bullet$ & 0 \\
0 & 0 & $\bullet$ & 0 \\
0 & 0 & $\bullet$ & 0 \\
0 & 0 & $\bullet$ & $\bullet$ \\
0 & 0 & 0 & \\
\hline
\end{tabular}

The similarities in the main issues of water category are: Water Efficient Landscaping, Water Use Reduction. The differences in the main issues of water category are:

I. LEED: added more additional issues for water category which are: Innovative Wastewater Technologies., outdoor water reduction, indoor water reduction, water metering, and cooling tower.

II. Australia: added new additional issues which are: Solar collectors, Hot water rating load, Measurements, water reuse.

III. ESTIDAMA: added new additional issues in water which are: Community Water Strategy, Building Water Guidelines, Water Monitoring \& Leak Detection, and Community Water Use Reduction Community Water Use Reduction: Water Features, Storm water Management, Water Efficient Buildings \& Plots.

IV. QSAS: added additional issue in water, which is Water Consumption.

\section{MATERIALS:}

Table 15: Concluded that the materials are as follows:

Table 15. The materials

\begin{tabular}{|c|c|c|c|c|}
\hline $\begin{array}{l}\text { The Issues of each categories } \\
\text { 2-materials }\end{array}$ & $\begin{array}{l}\text { LEED } \\
\text { V4. }\end{array}$ & $\begin{array}{l}\text { Australia green star } \\
\text { rating system }\end{array}$ & ESTIDAMA & QSAS \\
\hline $\begin{array}{l}\text { Building Reuse, Maintain } 75 \% \text { of Existing Walls, } \\
\text { Floors \& Roof }\end{array}$ & $\bullet$ & $\circ$ & $\circ$ & ○ \\
\hline $\begin{array}{l}\text { Building Reuse, Maintain } 95 \% \text { of Existing Walls, } \\
\text { Floors \& Roof }\end{array}$ & $\bullet$ & ○ & $\circ$ & ○ \\
\hline $\begin{array}{l}\text { Building Reuse, Maintain } 50 \% \text { of Interior } \\
\text { Non-Structural Elements }\end{array}$ & & & & \\
\hline $\begin{array}{l}\text { Construction Waste Management, Divert } 50 \% \\
\text { from Disposal }\end{array}$ & $\bullet$ & O & 0 & 0 \\
\hline $\begin{array}{l}\text { Construction Waste Management, Divert } 75 \% \\
\text { from Disposal }\end{array}$ & $\bullet$ & $\bullet$ & $\circ$ & ○ \\
\hline Materials Reuse, $5 \%$ & • & • & 0 & 0 \\
\hline
\end{tabular}


Materials Reuse, $10 \%$

Recycled Content, 10\% (post-consumer $+1 / 2$

pre-consumer)

Recycled Content, 20\% (post-consumer $+1 / 2$

pre-consumer)

Regional Materials, 20\% Extracted, Processed \&

Manufactured Regionally

\section{Rapidly Renewable Materials}

\section{Certified Wood}

Basic Construction Waste Management

Reused or Certified Timber

Improved Construction Waste Management

Improved Operational Waste Management

Organic Waste Management

Hazardous Waste Management

Life Cycle Assessment (LCA)

Eco Content

Durability

Environmental management system

Product stewardship

Storage for recycling materials

\section{The similarities in the main issues of material category are:}

Construction Waste Management, Materials Reuse, Recycled Content, Regional Materials, Certified Wood., and The differences in the main issues of material categories are:

I. LEED v4: added more additional issues for material categories which are:

Building Reuse, Maintain 75\% of Existing Walls, Floors \& Roof, and Building Reuse, Maintain 95\% of Existing Walls, Floors \& Roof, Rapidly Renewable Materials, storage recycling, LCA, waste management, and raw materials. Construction waste management planning, building life cycle analysis, environmental products, use of raw materials, Australia rating system added.

II. Australia: added more additional issues for material categories, which are: Eco content, durability, environmental management system, product stewardship (reuse-recycle-repressing) and Modular design.

III. ESTIDAMA: They add new additional issues in material, which are: Basic Construction Waste Management, Reused or Certified Timber, Improved Operational Waste Management, Organic Waste Management, Hazardous Waste Management.

QSAS: added material recycling and material reuse.

\section{CONCLUSION OF THE COMMON CATEGORIES}

The common categories between the four systems are sustainable site, indoor environmental quality, material, water and energy and Innovation in design

The main categories of LEED V4 are: Site location (16 points), Sustainable site (10 points), indoor environmental quality (16 points), the energy (33points), the water (11 points), the material (13 points) and the innovation. The assessment method is based on each category has identified weighing (6 points), regional priority ( 4 points). Then the total numbers of points are 110 points.

The building certified as: Certified: $20-46$, Silver.50-59 points, Gold: $60-79$ points, Platinum: 80 -and above

Positive point of LEED's system that it has been a system developed since 2000 through 2013 and has been reviewed four times, where we now find LEED 2009, LEED V3 and LEED V4, and from time to time is 
announced in USGBC.org website of United state Green Building Council for members who are interested to share their experience to develop LEED process it takes about six months review1 and review 2 and review3 they listen to experts, professionals and users views towards improvement of the negative notes into possible positive issues.

In LEED v3 the sustainable site increased from 14 points to 26 points, more challenges were added, such as development density and community connectivity ( 5 points), alternative transportation(12 max), storm water design (2max) and site development up to 2 points.

In Water efficiency, water use reduction has been increased from 5 points to 10 points and adding water efficient landscaping (4max), innovation wastewater technologies up to 2 points and water use reduction up to 4 points $\max$.

In energy the total points increased from 17 points to 35 points while concentrating on optimize energy performance (19 points max), on site renewable energy ( 7 max), enhanced refrigerant management ( 2 points), measurement and verification $(3 \max )$ and green power 2 points.

In materials the total points is increased from 13 points to 14 points, the total points are increased from I point to 2 points in material reuse up to 2 points

In indoor environmental quality, the total points were not increased; they are still on 15 points levels.

Innovation increased from 5 points to 6 points.

(Haselbach, 2008), presented an introduction to sustainable construction and discussed LEED system and principles. (Council, 1996), discussed the environmental sustainable development main issues.

In addition LEED released LEEDV4 in July 2013, (Malin, 2013) discussed, in their report ,the new concept in LEED v4 and stated that LEED V4 has added integrative design process, Rain water management in Sustainable site category, LEED V4 provided Light pollution reduction; and in addition they have added Building envelop commissioning, Green Power and carbon offsets, as well as adding the whole building life cycle assessment, biomass raw materials, response to Mining, Health product, Measuring of VOCs. In Indoor Environment, special day light autonomy, acoustic performance, all these points were added to LEED V4 after fifth public comments through the period 10, 2012 to fall of 2013.

From this analysis we have concluded that the rating system is a developed system which improvement depends on the best practice from users and experts. In each version we have more challenges and the total points are increased to achieve a higher certificate

As well ; it contains sub issues that help in managing certain local and global problems, for example the local problems i.e. : storm water design in Sustainable site category; and examples for global problems that have an effect on the local environment heat island effect, smoke control and optimize energy performance.

\subsubsection{The Additional Categories Was Added by the Global Assessment Methods}

LEED: added regional priority, Innovation and Site location

Australia green star system provides new additional categories which are:

Management Credits addressed the adoption of sustainable development principles from project conception through design, construction, commissioning, tuning and operation:

Transportation Credits reward the reduction of demand for individual cars by both discouraging car commuting and encouraging use of alternative transportation

Land ecology: Credits address a project's impact on its immediate ecosystem, by discouraging degradation and encouraging restoration of flora and fauna.

ESTIDAMA: Urban community, integrated development process, Natural System.

Urban Community consist of : Plan 2030, Urban Systems Assessment, Provision of Amenities and Facilities, Outdoor Thermal Comfort Strategy, Minimum Pearl Rated Buildings Within Communities, Transit Supportive Practices, Neighbourhood Connectivity, Open Space Network, Accessible Community Facilities, Housing Diversity, Community Walk ability, Active Urban Environments, Travel Plan, Improved Outdoor Thermal Comfort, Regionally Responsive Planning, Pearl Rated Buildings Within Communities, Safe and Secure Community.

\section{Integrated development process consists of:}

Integrated Development Strategy, Sustainable Building Guidelines, Community-Dedicated Infrastructure Basic 
Commissioning, Life Cycle Costing, Guest Worker Accommodation, Construction Environmental Management, Sustainability Awareness.

\section{Natural System consists of:}

Natural Systems Design and Management Strategy Reuse of Land, Remediation of Contaminated Land, Ecological Enhancement, Habitat Creation and Restoration, Food Systems.

QSAS: Urban Community, Culture and economic value.

\section{Urban Community consists of:}

Proximity to Infrastructure, Transportation Load, Load on Local Traffic Conditions, Solid Waste Load, Pedestrian Pathways and Wastewater Load

\section{Culture and economic value:}

The building's cultural and economic values shall be maintained or enhanced

v. Encouraging designs to align with cultural identity and traditions

vi. Designing for seamless integration into the existing cultural fabric

vii. Planning for the use of local materials and workforce

viii. Encouraging sustainable business partnerships within the community

ix. Constructing a diverse mix of housing typologies

x. These new categories have been added to satisfy the need for connecting the design with local culture, economic and local community and local environment.

\subsubsection{Availability}

Availability needs to be usable on all of its project and building types. All the Global systems in this comparison are applicable in many of buildings type. See (Table 16) which concludes the availability as follows.

Table 16 . The availability of each system

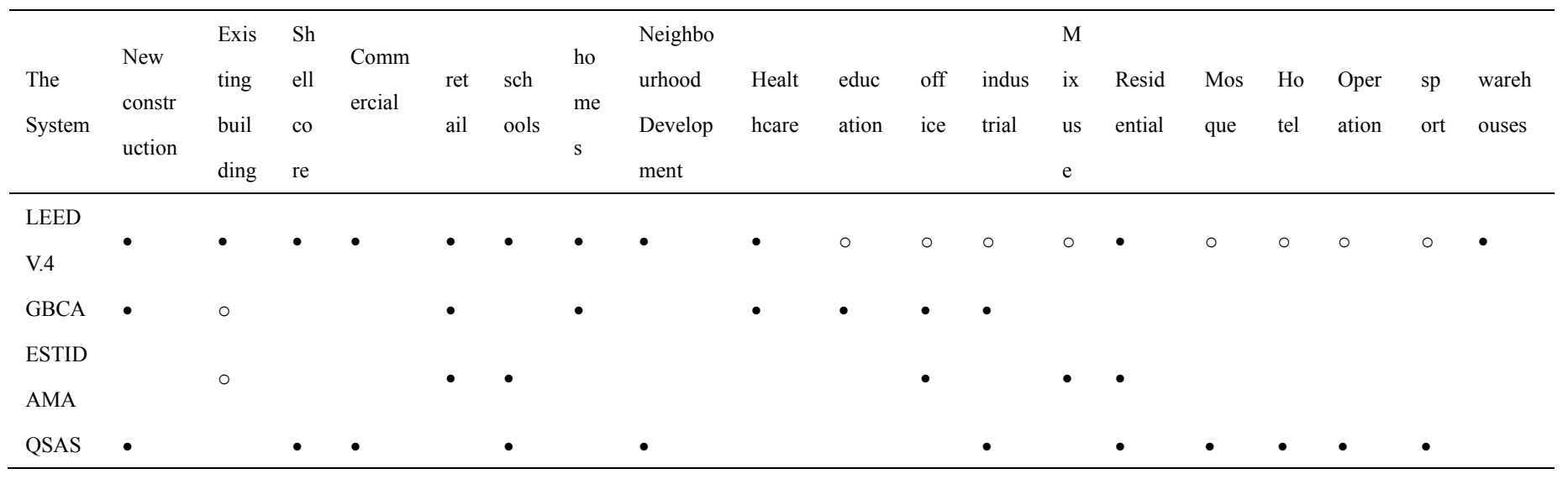

LEED: Applicable to new construction, existing buildings, commercial buildings, schools, neighbourhood, and healthcare. Warehouses, hospitals, data centres, mid-rise residential.

GBCA: Applicable to new construction, healthcare and education.

ESTIDAMA: new construction, schools, mix use, residential and retails

QSAS: new construction, commercial buildings, homes, schools, neighbourhood, residential, mosque, hotel, operation and sport.

\subsubsection{Applicability}

\section{Since when is this system applicable?}

Table 17 discusses the applicability of each system as follows: 
Table 17. The applicability of each system

\begin{tabular}{lllll}
\hline Applicability & LEED V4. & Australia green star rating system & ESTIDAMA & QSAS \\
\hline$\bullet$ & $\bullet$ & $\bullet$ & $\bullet$ \\
\hline
\end{tabular}

LEED: applicable since the year 2000 and they stated with LEED V1 on 2006, LEED V.2 in 2007, LEED V3 latest 2010 and LEED V4 latest 2012.

Australia: Applicable since 2008

ESTIDAMA: Applicable since 2009

QSAS: Applicable since 2009

\subsubsection{Development}

The study of the method of development will be carried out through Government, Private, Industry, NGO and Experts Opinion.

Table 18 shows the development of each system as follows:

Table 18. The development of the each system

\begin{tabular}{|c|c|c|c|c|}
\hline Development & LEED V4. & $\begin{array}{l}\text { Australia green star } \\
\text { rating system }\end{array}$ & ESTIDAMA & QSAS \\
\hline Government & $\bullet$ & - & $\bullet$ & $\bullet$ \\
\hline private & $\bullet$ & $\bullet$ & $\bullet$ & $\bullet$ \\
\hline industry & $\bullet$ & $\bullet$ & $\bullet$ & $\bullet$ \\
\hline NGOs & $\bullet$ & $\bullet$ & $\bullet$ & $\bullet$ \\
\hline Expert opinion & $\bullet$ & $\bullet$ & $\bullet$ & $\bullet$ \\
\hline
\end{tabular}

LEED: developed by the U.S. Green Building Council member committees. The U.S. Green Building Council is a non-profit organization.

GBCA: developed by GBCA.

ESTIDAM: developed by Abu Dhabi Urban planning council.

QSAS: developed by Gulf Organization for research and development. subsidiary of QATARI DIAR Real Estate Investment Company) - is a fully governmental Organization located at the Qatar Science and Technology Park (QSTP); which objective is to promote healthy, energy \& resources efficiency, and environmentally responsible building practices in Qatar and the entire Gulf region.

5.1.11 Durability

The life cycle analysis is provided or not?

(Table 19) shows the durability of each system through LCA

Table 19. The durability of the system

\begin{tabular}{lllll}
\hline Durability & LEED V4. System & Australia green star rating system & ESTIDAMA & QSAS \\
\hline LCA & Applicable & N/A & N/A & N/A \\
\hline
\end{tabular}

(Roaf, 2001) defined the life cycle analysis as:

"Life cycle analysis: It is used as a way of assessing the total impact of any building and shows the importance of the building's lifespan. The longer a house can last, the lower the impact of the energy and pollution resulting from the manufacture of its materials will be. A simple way to think about this is to consider the initial embodied energy of an entire building and divide this figure over its lifetime, making an allowance for maintenance".

We should provide the LCA for each material, products and manufacturer's warranty. 
Eco building materials are preferred, recycling materials, re-use, re-processing.

I. LEED: LCA is applied to LEED V4, in manufacture of building materials

and equipment, recycling/ reuse process.

II. Australia: LCA not applicable

III. ESTIDAMA: LCA not applicable

IV. QSAS: not applied LCA.

\section{PART II: IN DISCUSSION AND ANALYSIS}

\subsection{Additional Categories from Researcher Point of View for Hot Dry Climate}

\subsubsection{The Location and the Environmental Issues}

The second part of the study introduces additional categories suitable for hot dry climate; which are not presented by the four global systems. The location of the case study carried out in Greater Khartoum city, which consists of the three towns, the capital Khartoum, Khartoum North city and Omdurman city. It is located between latitude $15^{\circ} 36^{\prime}$ north and longitude $32^{\circ} 3$ east, with an altitude of 380 meters above sea level.

The climate described as hot dry climate, the temperature in summer ranges between $40^{\circ} \mathrm{C}$ to $45^{\circ} \mathrm{C}$, in winter it drops to $14^{\circ} \mathrm{C}$ to $25^{\circ} \mathrm{C}$. rainfall ranges between $100 \mathrm{~mm}$ to $150-\mathrm{mm}$. Relative humidity is $40 \%$ to $60 \%$. of Greater Khartoum area is experiencing floods, desertification and rare earthquakes. Wide variety of natural vegetation's covers the surrounding lands of the River Nile.

\subsubsection{Health Safety and Emission}

\section{None of the four Global Rating Systems provides health safety and emission as important Category.}

Health safety and emission are the most important categories to be added and therefore, healthy houses, minimized emission of $\mathrm{CO}^{2}$, and use of nontoxic building materials, should be provided to ensure secure building safety procedures. Focusing on the direct application of techniques and strategies that advance the concept of sustainable design, as defined above. All these topics deal with or affect the health, safety and welfare of the public and the communities at large.

\section{Health}

Roof, S., Fuentes M. and Thomas (2001) S. Op cit, discussed human health, asbestosis, asthma, and allergic skin reactions to asbestos exposure, non toxic building material and provision of impervious dust screen.

\section{Safety procedure}

(Pank, 2002) discussed safety procedures in building sector like: Enhancement of earthquakes resistance and adoption of Fire Safety Engineering. Fire safety engineering is a relatively new discipline, which has developed in recent years especially, to meet fire control solutions in buildings that fall outside of the current codes such as large and complex buildings demonstrate that the proposed fire solutions meet, or outperform the requirements of the intent of the regulations.

\section{Building is Permanent Fire Brigade.}

Although it is not mandatory, additional security measures have been adopted against fire accidents and have developed firefighting by stationing of firefighting crews in the UK, other European countries, such as Fraermanepntly stationed, within the building.

\section{Phased Evacuation.}

Protected escape routes in tall buildings must be managed effectively. To avoid excessively wide escape stairs, needed to evacuate several thousand people at the same time, phased evacuation is common. In this regard, the services within the building are shut down on the floor, where an alarm is raised together with one or two floors above and one floor below, and these floors are evacuated first. Fire protection of the building structure is related to evacuation times by a risk assessment approach - the longer the time for total evacuation of a building, the greater the provision for fire protection.

\section{Fire Fighting Shafts and Lifts}

For tall buildings, protected access within the building for fire fighting can be provided by the design of fire fighting shafts. Fire fighting lifts are currently used for heights greater than $18 \mathrm{~m}$. .

\section{Smoke Control}


Staircase pressurisation and smoke control systems are provided in fire rated airshafts. Smoke dampers activated by the Fire Alarm System are used in air conditioning and ventilation ducts.

\section{Sprinkler Protection and Gas Flooding Systems}

Sprinkler protection is provided throughout the building, as an automatic means of firefighting and controlling a fire during its initial growth. Gas flooding systems may be considered in specialist areas, such as computer data rooms, where sprinkler systems are undesirable.

\section{Emissions}

(Roaf, 2001) as well as, discussed gaseous emissions, in eco house we can avoid emissions by using exhaust fans, and clean energy in order to minimize $\mathrm{CO}_{2}$ emissions by proper ventilations. Carbon dioxide $\mathrm{CO}_{2}$, carbon monoxide $\mathrm{CO}$ in breathing and combustion inside the house, they are sources of air pollution, and Chlorofluorocarbons (CFCS).

In insulates, aerosols, refrigerants and fire extinguishers are responsible for destroying the ozone layer above the Earth that shields the planet from incoming radiation. (Roaf, 2001) stated that we should avoid toxic building materials such as PVC and use eco building materials in paints and plaster.

\subsubsection{The Outdoor Environment}

QSAS added the outdoor environment as new category in their FINAL DRAFT QSAS QUIDE (development, 2012). ESTIDAMA provides outdoor thermal comfort strategy inside liveable community category.

For Greater Khartoum it's very important to improve the outdoor thermal environment by controlling the design by providing shades to the building in North direction, South direction and enhance landscaping on sides with plants and trees that can provides more shades; fences protect the site from dust swimming pools and fountains modify the dry climate to humid climate. Khartoum residents take very much concern towards the outdoor environment where the climate is hot and dry. Khartoum residents spend part of their time, particularly nights times, in the gardens which are also enjoyed during holidays and celebrations.

\section{Ecological.}

(Lmdc, 2005) discussed thermal comfort in outdoor environment and said that: bringing people outdoors reduces demands for in indoor spaces and provides increased opportunities for contact with the natural world. Reduced demand on indoor spaces reduces indoor light and air conditioning energy requirements.

In order to improve their health, urban dwellers are required to increase their exercise activities and inhale more fresh air during daylight since they spend a large portion of their time staying indoors. As their contact with natural environment increases, their life-stress will be reduced, and more opportunities for rest and relaxation will be available to them. Creating opportunities for people to go outdoors and be in connection with nature will also arouse their awareness of these atmospheres and their role in sustaining them.

\section{Economic}

Increasing and extending the amount of time spent in comfortable outdoor spaces, provides increased and extended opportunities for outdoor retailing, dining have direct economic benefits in both, increased productivity and reduced medical costs.

\section{Social}

Outdoor spaces could enhance the level of social interaction that occurs in a neighbourhood. A comfortable outdoor space is likely to be utilized more frequently where increased presence of people outside boosts the security of the premises and contribute to deter crime.

\subsubsection{Landscape and Buildings Work Together}

(The Ministry of Environment, 2006) stated that perm culture adoption and application of organic techniques, rather than other techniques which could go against nature. The goal of permaculture is to create natural life supporting systems even in the smallest most urban areas. Healthier, more integrated environment results, when we combine the inherent qualities of plants and animals with the natural characteristics of landscapes and structure. (Shafiq, 2010) stated in his paper "Sustainability of Traditional and contemporary architecture' that uses of plants and trees reduce the cooling bill by $15-35 \%$ beside application of windows shades and sun screen from plants serve $10 \%$ of cooling system costs. 


\subsubsection{The Basic Understanding of Landscape Design and Its Elements}

(Awad, 2007) discussed in a paper, "The elements of landscape or landscape architecture design" and said that these elements are divided into two main parts: plants and trees, space of air mass, buildings, civil and mechanical construction, elements of landscape, ecological features.

\section{Conclusion of Outdoor Environmental Control:}

- In Sudan it is very important to improve the outdoor environment and provide thermal control

- provide shades and terraces and balconies

- provide swimming pools

- provide fountains

- maximize the outdoor environment in view of its physiological, ecological and economical and social aspect as specified, in order to make the air more humid and comfortable.

\subsubsection{The Building Form}

\section{None of the four Global systems Added Building Form as important Category.}

We have different buildings forms, cubic form, linear form, L-form, U- form, circular forms. There are many factors that compel and urge us to prefer a particular form over the others:

- Building location, whether the building is located on a top of a mountain or on flat land, cold areas or wet or hot dry climate each location requires specific form.

- The climate: whether the building is located in hot climate zone or cold climate. In cold areas it is better to use cubic form while in hot climate its preferred to use L-form or U-form or leaner form, as they provide good ventilation.

- The sun position: it is very important to study the sun movement in a specific location in order to determine the building form and shape. The building form secures more shades and minimizes the solar radiation.

- The Heat exchanger: The greater the volume of the building the more exposed surface area it has to lose or gain heat, Roaf, S., Fuentes M. and Thomas, S. ( 2001 ) discussed the building form in several cases such as: building as an analogy, the Ice House, the tea cosy cottage, the green house, the nomadic tents and the igloo. Figure 1 shows that different plan forms can have more or less wall area for the same plan area.

- The surface area: volume ratio is very important in conserving heat transfer into and out of a building. To conserve heat or cold, the building must be designed with a compact form to reduce the efficiency of the building as a heat exchanger. Buildings can have very different perimeters: area ratios depending on their plan form. (See figure. 1).
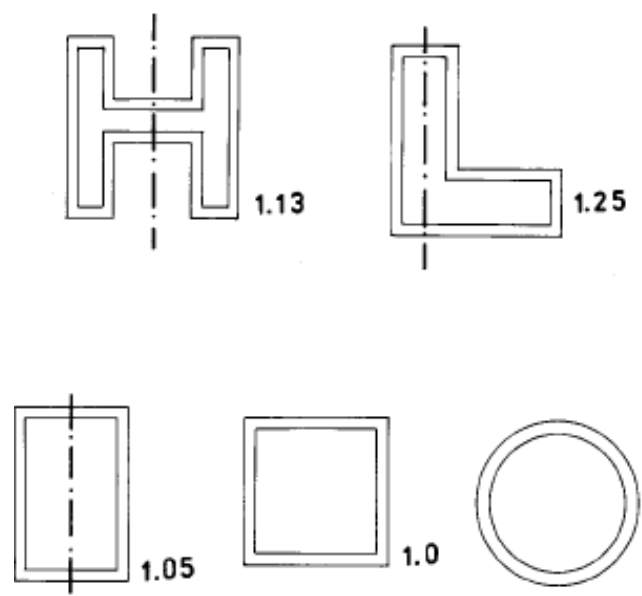

Figure 1. Buildings forms

Source: (Roaf, 2001).

- The building form also changes according to building function; we have found that linear form is suitable to schools, office buildings. The Cubic and $U$ form is suitable to hospitals and circular form is suitable to exhibitions. 
- $\quad$ Building information modelling (BIM) and energy simulation software are used to understand and predict the effect of building form on energy use for various design concepts in the early stages of the design.

- The orientation of the building should be perpendicular to the direction of the wind. It is worth to note that some experiments proved that greater velocities of the air could be obtained inside a building, if the orientation is kept at 45 degrees with the direction of the wind and offer more wind shaded area (Hassan, 2001) discussed the relation between building orientation and the wind direction and said that his good orientation of the building makes the house healthier, and by studying of sun rises and sun sets locations we shall be more knowledgeable of the direction of the shades made for the gardens and terraces.

- If we consider all the above mentioned criteria we can apply the sustainability and durability of the building.

The building form is developing through the history and people are always choosing the form suitable to their local environment and local climate. The nomadic tent shows a good example of an adaptable building form. (See Figure. 2) showing the buildings form and their orientation and surface volume Ratio.

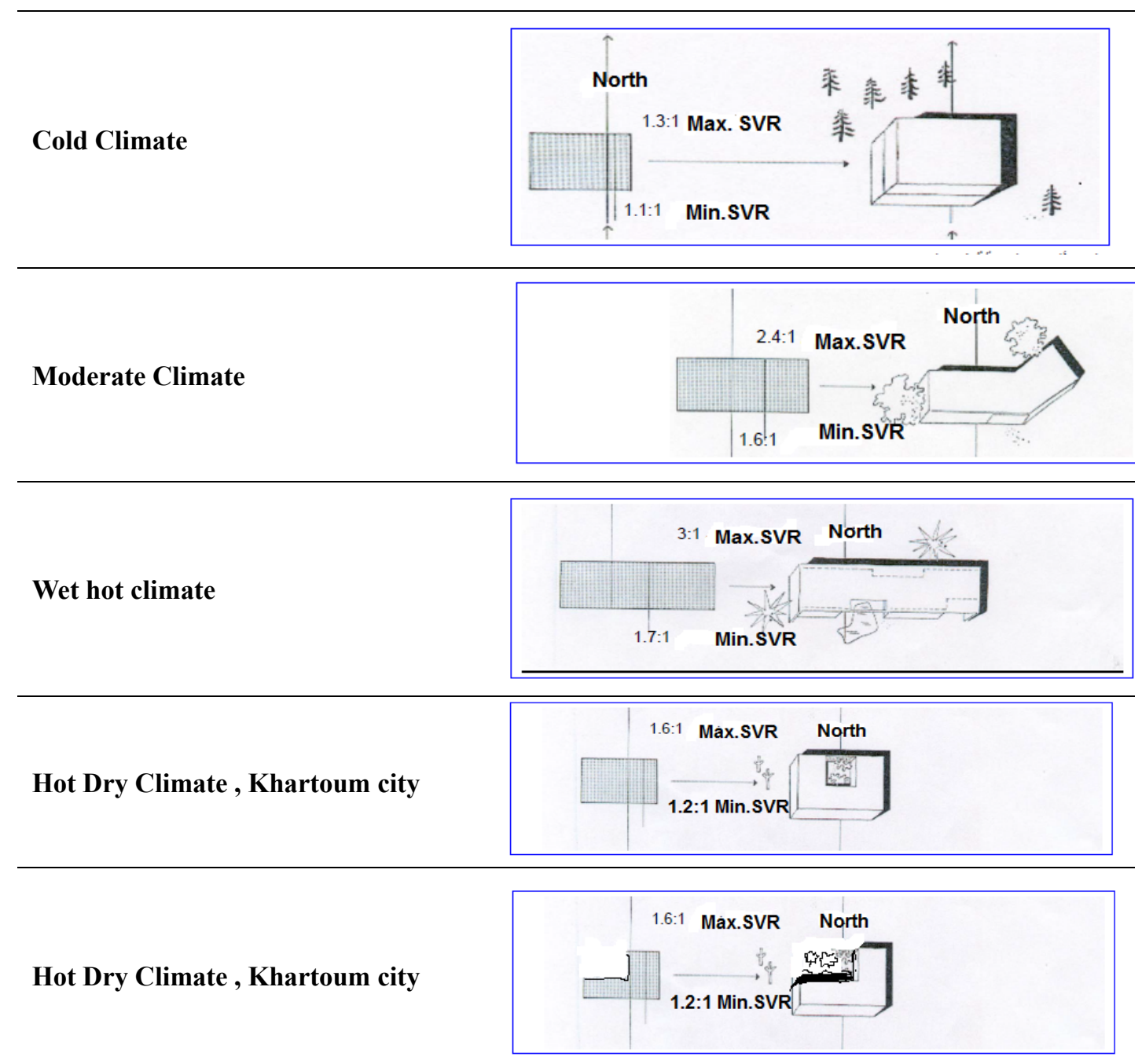

Figure 2. The Relation between building form and the surface volume ratio (SVR) and building orientation Source: (water, 2012)

\subsubsection{The Holism and Environmental Design Process}

\section{Holism}

The term holism has been used to describe the view that a whole system must be considered, rather than simply 
its individual components. The Vales have addressed this point in their book Green Architecture, suggesting that a building should attempt to address all of the principles of green design in a holistic manner (Vale and Vale, 1991). Holism emphasizes the relationship between the parts and the whole. Another dimension of holism comes from an engineering perspective and relates to the synergy between systems, which is a critical part of the physicality of a house. Holism can mean the way in which systems are integrated within the home - for example, the way, in which the solar system is integrated with the roof or, the water recycling system is integrated with the irrigation system. In summary, the outcome of holism can create and lead to greater improvements in environmental performance. (Hide, 2008)

Identify of the whole design process from the design initial stages and the design pass through three phases:

\section{Pre Building Phase:}

Pre building phase is the design phase, primary, developed and final design. Adoption of sustainable eco-building categories to be as main goals.

\section{Building phase:}

Building phase is in construction and operation system, in this level, dealing with contractors and suppliers apply appropriate technologies in mechanical system and construction waste disposal and control of noise in site.

\section{Post Building Phase:}

After building construction has been completed come the users' role who should observe regular maintenance of the building, in order to ensure building long life and durability. And improve of the Rating System through regular reviews by stakeholders and frequent survey by the users of the system in order to maintain and manage the difficulties.

\section{Acknowledgement}

This humble effort would not have been possible without the help of others. I would like to thank my supervisor Prof..Saud Sadig Hasan for his continues and exceptional help and guidance. I would also like to extend my thanks to Dr.Tallal Abdel Basit for reviewing my work. Editor and all reviewers for giving chance in publishing my work. I should also thank. Dar Al Uloom University/Saudi Arabia/Riyadh city.

\section{References}

Alhor, Y. (2009). Development of comprehensive Sustainability Rating System in Qatar (QSAS). Qatar, BQDR, Qatar..

Australia, G. B. C. O. (2016). Green Building Council Of Australia. Retrieved September 30, 2015, from www.g.b.c.a.

Awad, A. (2007). Towards an Understanding of the Role of Landscape Design. Khartoum, Sudan, Rethinking our Design Conference, Faculty of Architecture, University of Khartoum .

City, M. (2011). The Future Built. Retrieved September 30, 2015, from http://www.thefuturebuild.com/leed/page.htm

Council, A. D. P. (2010). Pearl Community Rating System Design \& Construction Version 1. ESTIDAMA Abu Dahabi Urban Planing Council ed. Abu Dhabi : Abu Dahabi Planning Council, UAE.

Council, A. D. U. P. (2016). Abu Dhabi Urban Planning Council. Retrieved September 30, 2015, from http://www.upc.gov.ae/home.aspx?lang=en-US

Council, E. G. B. (2007). Emirates Green Building Council. Retrieved September 30, 2015, from www.emirates.gbc.org

Council, S. A. G. B. (2013). South Africa Green Building Council. Retrieved from http://www.gbcsa.org

Council, U. S. G. B. (1996a). Sustainable Building Technical Manual", Green Building Design Construction and Operation. USGBC ed. USA: Public Technology Inc. U.S.A..

Council, U. S. G. B. (1996b). sustainable building technical manual, green building design and operation. In D. Gottfried (Ed.), green building design and operation (pp. 20). U.S.A: Public Technology Inc.

Council, U. S. G. B. (2016). United State Green Building Council. Retrieved from http:www.usgbc.org

Development, G. O. O. R. A. (2012). QSAS Technical Guide, Qatar : QSAS.

Diar, Q. (2010). Developing a sustainablity rating system in GCC the Experience from Qater. Riyadh, Saudi Green Building Forum, Riyadh City, KSA. 
Fenner, R. A. R. T. (2008). A Comparative Analysis of two Building Systems. Canada, Engineering Sustainability, 161.

Fowler, K. A. R. E. (2006). Sustainable Building Rating Systems Summery. USA: US Department of Energy.

Haapio, A. A. V. P. (2007). A Critical Review of Building Environmental assessment tools. TKK, Finland, ELSEVIER.

Haselbach. L. (2008a). The Engineering Guide to LEED New Construction (Mac Craw Hill ed.). New York: Mac Craw Hill Press.

Haselbach, L. (2008b). The Engineering Guide to LEED New Construction (1st ed.). New York: Mc Craw Hill Press.

Hassan, S. (2001). The Principles of Environmental Urban Science. Khartoum, Sudan, 1 st, Sudan for Science and Technology University.

Hide, R. (2008). Bioclimatic Housing inovateive Design For warm climates (1st ed.). UK: Cromwell Press.

Lmdc, P. A. N. (2005). Outdoor Environmental Comfort, Sustainable Design Guidelines Refrence Manual. UK: WTC redevelopment Projects, Croxton Collaborative Architects, PC.

Malin, N. A. M. P. A. R. T. (2013). New Concepts in LEED V4 , USA: Building Green Inc.

Ministry for Environment, H. C. C. a. A. R. C. (2006). Easy Guide to Eco Building Design and Live with the environment (1st ed.). USA: BRANZE Press.

Pank, W. G. H. a. C. G. (2002). Tall Buildings and Sustainability, Corporation of London. UK: Corporation of London.

QSAS. (2016). Qatar sustainability assessment system.Retrieved from www.qsas.org

Rick, A. (2012). The Architecture of Green Building Designing State of the Sustainable Structure for the Middle East Environment Culture and Heritage. KSA, 3 rd Saudi Green Building Forum .

Roaf, S. F. M. a. T. S. (2001). Eco House A Design Guide. Architectural Press ed. UK: Architectural Press.

Shafiq, J. (2010). Sustainability of Traditional and Contemporary Architecture. KSA, Riyadh city, Conference on Technology and Sustainability in the Built Environment, King Saud University .

Steemers, K. a. S. M. (2004). Environmental Diversity in Architecture (1st ed.). UK: Spoon Press.

Thaimosy, M. a. F. M. S. S. H. P. (2006). A Comparision of The LEED and Geen Globes System. CANADA, The Carpenters Industerial Council (CIC).

Thomas, R. a. M. F. (2006). Environmental Design An Introduction for Architects and Engineer (2nd ed.). USA: Taylor \& Francis Group.

UNEP. (2012). 21 Issues for the 21st Century, USA , www. ECo Builders : UNEP Eco Cities Emerging Magazine.

WAN, Y. (2014). Analysis of the International Sustainable building Rating System for Sustainable Development with special focused on Green Building Index Malysia (GBI). Malaysia, Faculty of Technology and Management .

Water, T. M. o. E. a. (2012). Rationalization Guide book. KSA, Riyadh City, The Ministry of Electricity and water.

\section{Copyrights}

Copyright for this article is retained by the author(s), with first publication rights granted to the journal.

This is an open-access article distributed under the terms and conditions of the Creative Commons Attribution license (http://creativecommons.org/licenses/by/3.0/). 